\title{
Numerical Analysis of the Mechanical Properties of a Vena Cava Filter
}

\author{
Kazuto Takashima ${ }^{1,2}$, Koji Mori³ ${ }^{3}$ Kiyoshi Yoshinaka ${ }^{4}$ and Toshiharu Mukai² \\ ${ }^{1}$ Kyushu Institute of Technology \\ 2RIKEN \\ ${ }^{3}$ Yamaguchi University \\ ${ }^{4}$ National Institute of Advanced Industrial Science and Technology \\ Japan
}

\section{Introduction}

When anticoagulants are contraindicated for the venous thromboembolism therapy and thromboembolism recurs, a vena cava filter is inserted percutaneously into a major vein in order to prevent blood clots from entering the lungs (Ando \& Kuribayashi, 2000; Streiff, 2000) (Fig. 1). The inferior vena cava filter is a mesh structure designed to capture blood clots while not impeding blood flow. This filter is inserted using an introducer catheter from either the femoral or jugular vein and is fixed by a hook attached to the tip of a wire. Several filters have been designed to lyse captured clots.

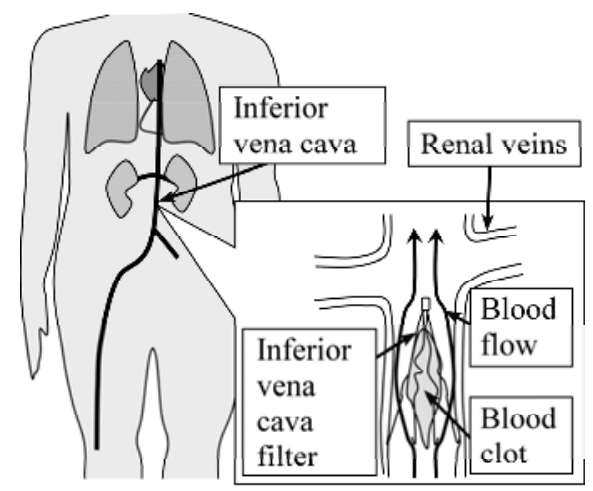

Fig. 1. Placement of the inferior vena cava filter.

Ideally, the filter should capture blood clots efficiently while not impeding the blood flow. Moreover, the filter should not move in the blood vessel after deployment and should pass smoothly through the slim introducer catheter. Although insertion appears to be a safe and effective method by which to prevent the recurrence of pulmonary embolism, patients in whom the filter has become tilted may experience pulmonary embolism recurrence because of a decrease in the thrombus-trapping performance of the filter (Nara et al., 1995; Rogers et 
al., 1998). In order to satisfy these requirements, several types of filters, such as permanent, temporary, and retrievable filters, have been proposed. For example, several types of vena cava filters, such as Greenfield filter, Vena Tech filter, Bird's nest filter, Simon-Nitinol filter, TrapEase filter, Günther tulip filter, Antheor filter, Neuhaus protect filter, and RecoveryNitinol filter, have been developed (Ando \& Kuribayashi, 2000; Boston Scientific, 2007; Greenfield et al., 1990, 1991; Kinney et al., 1997; Nara et al., 1995; Rogers et al., 1998; Streiff, 2000; Swaminathan et al., 2006). However, there are few quantitative data on the mechanical properties of these filters. In particular, although Swaminathan reported the blood clot capturing efficiency from the viewpoint of computational fluid dynamics (Swaminathan et al., 2006), there are few quantitative data concerning, for example, the ease of filter delivery. Therefore, in the present study, we evaluated through numerical analysis the mechanical properties of a Greenfield filter deployed into a vein. In particular, since the filter expands rapidly, the surgeon cannot perceive the expanding motion or the transition of the contact force applied to the blood vessel wall. Therefore, a complete understanding of the mechanical properties of the filters must be determined on not only input from doctors but also on the results of numerical analysis regarding the expansion. These methods are expected to be useful for analyzing the structure of filters and may help to guide the design of new filters.

Based on the above considerations, we herein evaluate by numerical analysis the dynamic motion of a deployed filter using the evaluation standard of the incline and misalignment between the filter and the blood vessel. First, we evaluated whether the filter tilts when the catheter tilts or is misaligned or when the filter cannot expand. Second, we evaluated the migration of the deployed filter under a constant force.

\section{Methods}

Catheters and guidewires are used in the treatment of infarctions and aneurysms. In a previous study, in order to make intravascular treatment safer, we developed a computerbased surgical simulation system in order to simulate a catheter placed inside blood vessels for treatment of the brain (Takashima et al., 2006, 2007b, 2009). In the present study, we applied the simulation methods for the guidewire to the inferior vena cava filter because both the guidewire and the inferior vena cava filter are flexible structures. Using a similar model, we can easily combine the filter model with our catheter simulator. Actually, a catheter simulator has been developed as a training environment for inferior vena cava filter placement (Hahn et al., 1998). Ease of percutaneous filter delivery provides numerous advantages to both doctors and patients, including improved operational efficiency and reduced cost. Therefore, it is important that the filter be easy to use in combination with a catheter.

\subsection{Filter model}

In the present study, we used a Greenfield filter (GF) constructed of titanium (Fig. 2) (Ando \& Kuribayashi, 2000; Boston Scientific, 2007; Greenfield et al., 1990, 1991; Kinney et al., 1997; Nara et al., 1995; Rogers et al., 1998; Streiff, 2000; Swaminathan et al., 2006). This permanent filter is commonly used in Japan. The GF is constructed of either titanium or stainless steel and come in various shapes. The GF used herein is cone-shaped and consists of six wires connected to a head. The diameter of the wires is $0.45 \mathrm{~mm}$ (Swaminathan et al., 2006), and each leg has a "zigzag" pattern. The bottom diameter of the cone is $38 \mathrm{~mm}$ (Greenfield et al., 
1991). The total length of the GF is $47 \mathrm{~mm}$ (Greenfield et al., 1991). We used a head without a hole and determined the diameter $\left(2 R_{\mathrm{h}}\right)$ and length $\left(L_{\mathrm{h}}\right)$ of the head by measurement. The over-the-wire filter has a head with a small hole and inserted over the guidewire to optimize the alignment of the filter with the inferior vena cava (Kinney et al., 1997).

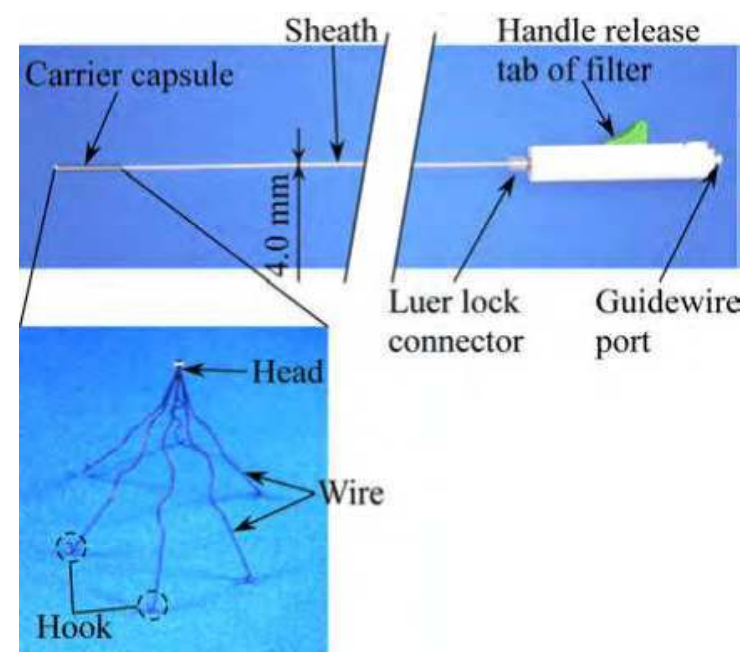

Fig. 2. The Greenfield inferior vena cava filter.

This model of the filter is constructed with viscoelastic springs and $n$ segments for the dynamic deformation of a flexible structure. The viscoelastic springs express the bending and torsional stiffness of the wire. The motion of the filter model is represented by the Newton-Euler equations of motion as follows:

$$
\boldsymbol{M}(\boldsymbol{q}) \ddot{\boldsymbol{q}}+\boldsymbol{V}(\boldsymbol{q}, \dot{\boldsymbol{q}})=\sum_{i}^{n} \boldsymbol{J}_{\mathrm{r}}^{\mathrm{T}}(\boldsymbol{q}) \boldsymbol{F}_{\mathrm{i}}-\boldsymbol{K}\left(\boldsymbol{q}-\boldsymbol{q}_{\mathrm{o}}\right)-D_{\mathrm{w}} \dot{\boldsymbol{q}}
$$

where $\boldsymbol{q}$ is the joint displacement vector, $\boldsymbol{q}_{\mathrm{o}}$ is the joint displacement vector when no load is applied, $\boldsymbol{M}(\boldsymbol{q})$ is the inertia matrix, $\boldsymbol{V}(\boldsymbol{q}, \dot{\boldsymbol{q}})$ is the centrifugal force (Coriolis force), $\boldsymbol{F}_{\mathrm{i}}$ is contact force vector of each segment $(i)$, and $K$ and $D_{\mathrm{w}}$ are elastic and viscous coefficients of a mobile joint, respectively. The second and third terms of the right-hand side in this equation correspond to the viscoelastic forces of a mobile joint. The head and the wire of the filter consist of one and three segments (diameter: $2 R_{\mathrm{w}}$, length: $L_{\mathrm{w}}$ ), respectively. Each segment of the wire has a mobile joint in the center. The elastic coefficient of the mobile joint $(K)$ with respect to bending resistance $\left(K_{\mathrm{wx}}\right)$ and torsional resistance $\left(K_{\mathrm{wz}}\right)$ are approximated as follows (Yamamura et al., 2003):

$$
\begin{aligned}
& K_{\mathrm{wx}}=E_{\mathrm{w}} I_{\mathrm{x}} / L_{\mathrm{w}} \\
& K_{\mathrm{wz}}=G_{\mathrm{w}} I_{\mathrm{p}} / L_{\mathrm{w}}
\end{aligned}
$$

where $E_{\mathrm{w}}$ and $G_{\mathrm{w}}$ are Young's modulus and the modulus of transverse elasticity of the wire of the filter, respectively, $I_{\mathrm{x}}$ and $I_{\mathrm{p}}$ are the area moment of inertia and the polar moment of 
inertia of area, respectively. In the present study, since the wire is a rod (radius: $R_{\mathrm{w}}$ ), $K_{\mathrm{wx}}$ and $I_{\mathrm{p}}$ are expressed as follows:

$$
\begin{gathered}
K_{\mathrm{wx}}=\Pi E_{\mathrm{w}} R_{\mathrm{w}} 4 / L_{\mathrm{w}} \\
I_{\mathrm{p}}=2 I_{\mathrm{x}}
\end{gathered}
$$

Assuming an isotropic material, $G_{W}$ is expressed using Poisson's ratio $(v)$ as follows:

$$
G_{\mathrm{W}}=E_{\mathrm{w}} / 2(1+v)
$$

In the present study, $v=0.3$ (Petrini et al., 2005).

The parameters and dimensions of the filter model are shown in Table 1 and Fig. 3, respectively. In this table, subscripts $w$ and $h$ indicate the parameters of the wire and the head, respectively. Here, $K_{\mathrm{wx}}$ and $K_{\mathrm{wz}}$ are obtained by substituting $R_{\mathrm{w}}$ and $E_{\mathrm{w}}$ in Table 1 into Eqs. (2) and (3). Assuming a fixed joint, the values of the joints between the wire and the head are 100 times as large as those obtained using Eqs. (2) and (3). The recurved hook is set at an angle of $80^{\circ}$ (Greenfield et al., 1991). The actual leg hook consists of a twisted and complicated structure in order to avoid migration of the filter after deployment or penetration of the vein (Greenfield et al., 1990, 1991) (Fig. 2). However, since the penetration of the vein was not evaluated in the present study, the bending number of the hook is one. The change of the bending angle is equal to the change of $q_{0}$, as shown in Eq. (1). In a manner similar to the catheter simulator (Takashima et al., 2006, 2007b, 2009), the viscous term for each movable joint was considered in terms of $D_{\mathrm{w}}$. Since we cannot measure the exact values, we assumed $D_{\mathrm{w}}$ to be smaller than $K_{\mathrm{wx}}$ and $K_{\mathrm{wz}}$. We neglected the "zigzag" pattern and the slight flare of the wire. In the design of the titanium GF, the addition of a slight flare to the legs was made in order to facilitate discharge from the carrier without leg crossing, particularly from the jugular direction where the legs discharge first (Greenfield et al., 1990).

\begin{tabular}{|c|c|}
\hline$R_{\mathrm{w}}(\mathrm{mm})$ & 0.225 \\
\hline$R_{\mathrm{h}}(\mathrm{mm})$ & 0.875 \\
\hline$E_{\mathrm{w}}(\mathrm{GPa})$ & 22 \\
\hline Density $\left(\mathrm{g} / \mathrm{cm}^{3}\right)$ & 5.3 \\
\hline$D_{\mathrm{w}}(\mathrm{N} \cdot \mathrm{m} \cdot \mathrm{s} / \mathrm{rad})$ & 0.005 \\
\hline$L_{\mathrm{w}}(\mathrm{mm})$ & 4,43 \\
\hline$L_{\mathrm{h}}(\mathrm{mm})$ & 2 \\
\hline$n$ & 25 \\
\hline
\end{tabular}

Table 1. Parameters of the filter model used in simulation.

\subsection{Blood vessel model}

The vessel is a circular elastic cylinder defined by a centerline and a radius $\left(R_{\mathrm{v}}\right)$. The centerlines are represented by numerical data. The position of the centerline of the vessel is constant. The contact forces between the filter and the vessel are calculated according to the stiffness and the friction of the vessel wall. The friction force are derived from the fixation of the hook. Moreover, the diameter of the blood vessel $\left(2 R_{\mathrm{v}}\right)$ is assumed to be $20 \mathrm{~mm}$, which is similar to Swaminathan (Swaminathan et al., 2006). In the instructions for the use of the GF (Boston Scientific, 2007), the maximum diameter of the inferior vena into which the filter can be deployed is $28 \mathrm{~mm}$. 
The simulation models used in the present study are shown in Fig. 4. The centerline of the blood vessel is along the $z$-axis.

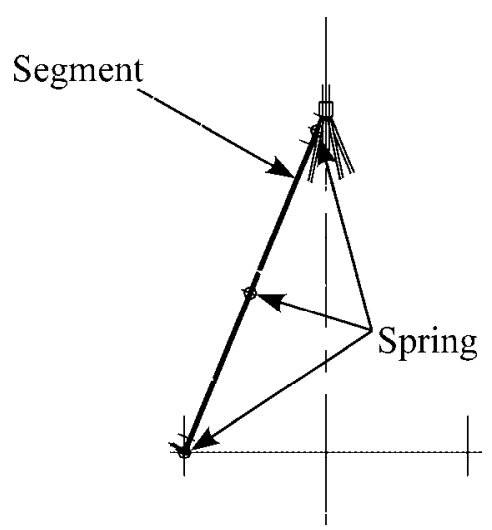

Fig. 3. Dimensions of the filter model (unit: $\mathrm{mm}$ ).

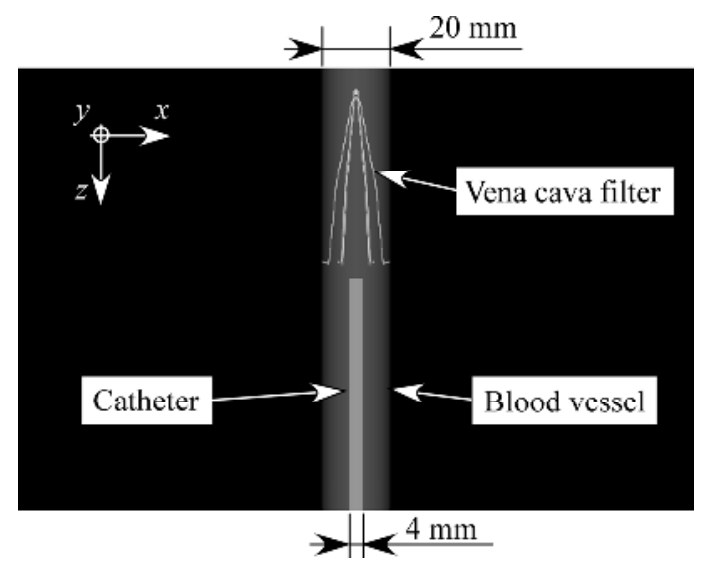

Fig. 4. Simulation model (vena cava filter, catheter, and blood vessel).

\subsection{Calculation of contact force}

In order to determine whether contact occurs between the filter and the vessel, the distances between the joints and the tip of the filter model $\left(p_{\mathrm{i}}\right)$ and the centerline of the vessel, were calculated. Considering the clearance of the filter and the blood vessel, we calculated the contact force according to the distance. Here, $\boldsymbol{F}_{\mathrm{i}}$ is decomposed into three components along the centerline of the blood vessel $\left(f_{\mathrm{ti}}\right)$, the normal direction to the centerline $\left(f_{\mathrm{ni}}\right)$, and the circumferential direction of the cross-section $\left(f_{\mathrm{ri}}\right) \cdot f_{\mathrm{ni}}$ is expressed as follows:

$$
f_{\mathrm{ni}}=-K_{\mathrm{v}}\left(\left|l_{\mathrm{i}}\right|+R_{\mathrm{W}}-R_{\mathrm{v}}\right)^{3 / 2} l_{\mathrm{i}} /\left|l_{\mathrm{i}}\right|
$$

where $K_{\mathrm{v}}$ is the elastic coefficient of vessel deformation and $l_{\mathrm{i}}$ is the distance vector between each joint and nearest point on the central curve of the blood vessel. 
In our previous studies (Takashima et al., 2006, 2007b), we assumed that the frictional force is opposite the direction of motion. In other words, the model includes only dynamic friction, and there is no friction when the model does not move. However, the titanium GF has an improved hook design and does not move at the contact position (Greenfield et al., 1990, 1991). As a preliminary test, we measured the resistance force that occurs when the head of a commercial GF is pushed and pulled in acryl and silicon rubber tubing (inner diameter: $20 \mathrm{~mm}$ ). The maximum resistance force is summarized in Table 2. In this table, when the GF is pulled, the force acts in the direction of blood flow after deployment (along the -z-axis in Fig. 4). Since the mass of the GF is $0.3 \mathrm{~g}$ (measured value), this resistance force is very large. Moreover, the resistance force in the silicon rubber tubing changed according to the direction of the applied force because of the hook biting into the wall of the tubing. Therefore, taking the bite of the hook into consideration, we approximated the constraint force of the tip of the wire on the blood vessel wall as follows.

1. After the tip of the wire contacts the blood vessel wall, the contact point $\left(\boldsymbol{r}_{\mathrm{i}}\right)$ is calculated.

2. The expression $k_{\mathrm{i}}=p_{\mathrm{i}}-\boldsymbol{r}_{\mathrm{i}}$ is decomposed into the components along the surface of the blood vessel wall ( $\boldsymbol{k}_{\mathrm{ti}}$ and $\boldsymbol{k}_{\mathrm{ri}}$ are the components along the centerline and in the circumferential direction of the cross-section, respectively). Using a constant $\left(K_{\mathrm{f}}\right)$, the contact force is calculated as follows:

$$
\begin{aligned}
& f_{\mathrm{ti}}=-K_{\mathrm{f}} \boldsymbol{k}_{\mathrm{ti}} \\
& f_{\mathrm{ri}}=-K_{\mathrm{f}} \boldsymbol{k}_{\mathrm{ri}}
\end{aligned}
$$

where $r_{\mathrm{i}}$ is calculated whenever the contact condition is changed. In the present study, we calculated the conditions without the constrained force approximated by Eqs. (8) and (9). The actual condition may lie somewhere between the conditions with and without the constraint force.

\begin{tabular}{|c|c|c|}
\hline Tubing material & Push (N) & Pull (N) \\
\hline Acryl & 0.4 & 0.2 \\
\hline Silicon rubber & 0.4 & 1.4 \\
\hline
\end{tabular}

Table 2. Friction force required to move the Greenfield filter in acryl and silicon rubber tubing.

The parameters for simulation are summarized in Table 3. The value of $K_{\mathrm{v}}\left(=32 \mathrm{~N} / \mathrm{mm}^{3 / 2}\right)$ was determined from the experimental results using a porcine aorta (Takashima et al., 2007a). Moreover, along the surface of the blood vessel wall, we assumed that $K_{\mathrm{f}}=32$ $\mathrm{N} / \mathrm{mm}$. As shown in Fig. 4, the filter model was initially inserted into the introducer catheter model. The inner diameter of the catheter model is $12 \mathrm{Fr}$. The catheter model is fixed along the $z$-axis at $z>0$ and is assumed to be a rigid tube. In the catheter, the contact force is calculated with respect to the catheter, and we approximated $K_{\mathrm{v}}$ as $20,000 \mathrm{~N} / \mathrm{mm}^{3 / 2}$, because the catheter is more rigid than a blood vessel. There is no friction in the catheter. Using these models, the position and the configuration of the filter were calculated in order to model the deployment of a GF inside a blood vessel and the existence of the GF for a fixed time under a constant force. 


\begin{tabular}{|c|c|}
\hline$R_{\mathrm{v}}(\mathrm{mm})$ & 10 \\
\hline$K_{\mathrm{v}}\left(\mathrm{N} / \mathrm{mm}^{3 / 2}\right)$ & 32 \\
\hline$K_{\mathrm{f}}(\mathrm{N} / \mathrm{mm})$ & 32 \\
\hline
\end{tabular}

Table 3. Parameters of the vessel model used in the simulation.

\subsection{Simulation procedure}

The simulation procedure is as follows (Fig. 5).

1. The filter model is initially inserted into the introducer catheter model (12 Fr) (Fig. 5, left).

2. The filter is moved axially and is freed from the catheter (Fig. 5, center). The filter model is made to contact the blood vessel wall for $10 \mathrm{~s}$ (Fig. 5, right).

3. Assuming the blood flow and gravity, the filter inside the blood vessel is applied for a fixed time $(60 \mathrm{~s})$ under a constant force along the $z$-axis.

The GF is deployed with the head downstream. Therefore, the direction in the introducer catheter changes according to the insertion site (from the femoral vein or the jugular vein). In the present study, we inserted the catheter from the femoral vein.
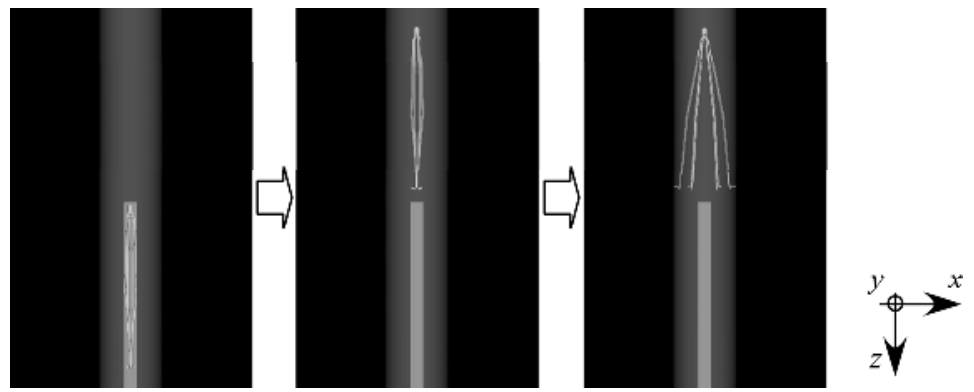

Fig. 5. Insertion procedure.

When large clots occlude the filter, the effects of the filter wires and the head on the flow would be negligible in comparison with the effects of the large particles because the wires are thin and the head is behind the blood clot. Moreover, since the pulsatility of the blood flow in the inferior vena cava is relatively low and is a low-pressure system, we assumed a constant, time-averaged flow (Swaminathan et al., 2006). Under the above assumptions, we calculated the drag $(D)$ generated by the blood flow considering a ball (diameter, $d$ ) in a uniform flow, as follows (Tagori \& Arakawa, 1989):

$$
D=C_{\mathrm{D}}(1 / 2) \rho U^{2}(\Pi / 4) d^{2}
$$

where $C_{\mathrm{D}}$ is the drag coefficient, $\rho$ is the fluid density, and $U$ is the fluid velocity. Similar to Swaminathan (Swaminathan et al., 2006), we assumed that $\rho=1,040 \mathrm{~kg} / \mathrm{m}^{3}, U=0.123 \mathrm{~m} / \mathrm{s}$, $d=5 \mathrm{~mm}$, and Reynolds number, $R e=1,000$. Moreover, using $R e=1,000$, we obtained $C_{\mathrm{D}}=$ 0.4 (Tagori \& Arakawa, 1989). Substituting these values into Eq. (10), we obtained $D=0.06$ $\mathrm{mN}$. Since the mass of the filter is $0.3 \mathrm{~g}$, the gravity applied to the filter is $3 \mathrm{mN}$. Therefore, the force generated by the blood flow is much smaller than that generated by gravity, although the force depends on the size of the blood clot. On the other hand, since the friction model used in the present study is independent of the direction of the hook, we evaluated 
the migration of the filter considering the safety factor when the gravity doubled (i.e., assuming a gravitational acceleration of $-19.61 \mathrm{~m} / \mathrm{s}^{2}$ along the $z$-axis). Experiments in sheep (Greenfield et al., 1990) have demonstrated migration of the filter in both directions, and whether this migration is caused by gravity or blood flow remains unclear.

Based on the above assumptions, we calculated the Newton-Euler equations of motion (Eq. (1)) using the contact force at every finite time step, using numerical differentiation formulas (NDF). The time steps were not fixed in order to make the relative errors smaller than permissible values $\left(10^{-3}\right)$ at each time step. When contact occurred within a time step, we divided the time step at the contact point. This numerical analysis was performed in a MATLAB/Simlink (Cybernet Systems Co., Ltd.) environment.

\subsection{Calculation conditions}

Complications after filter deployment include the migration of the filter, fracture of the wire legs, penetration of the filter, deployment of the filter in an improper position, and retroperitoneal hematoma (Ando \& Kuribayashi, 2000). Moreover, it has been reported that there is no recurrence of pulmonary embolism when the GF is secured without tilting in 13 patients (Nara et al., 1995). Since the hook of the GF has been improved and is fixed as soon as the filter comes into contact with the blood vessel wall, some asymmetry of the limbs may result (Greenfield et al., 1991). Moreover, it is difficult to retrieve the GF once it has been deployed. Therefore, it is necessary to continue anticoagulation therapy and to deploy another filter when the deployed filter is inclined (Nara et al., 1995).

In the present study, we evaluated the effects of the parameters of the filter model and the deployment condition on the simulation system as follows. Cases * 1 and *-2 stand for cases without and with fixation of the hook to the blood vessel model, respectively. When there is no friction, the analysis shown in procedure 3 of Section 2.4 was not performed.

- $\quad$ Cases 1-1 and 1-2: Normal condition

As a fundamental condition, we evaluated the motion of the filter when the axis of the introducer catheter is along the centerline of the blood vessel.

- Cases 2-1 and 2-2: The filter does not expand uniformly. Specifically, one wire cannot expand.

The filter does not expand uniformly when a leg of the filter is captured by a blood clot that occurred in the catheter (Ando \& Kuribayashi, 2000).

- Cases 3-1 and 3-2: The filter is deployed through a tilted catheter

The filter may tilt according to the approach angle of the catheter, which depends on the shape and curvature of the blood vessel (Ando \& Kuribayashi, 2000; Kinney et al., 1997). For example, in the case of right femoral approaches, a sheath caval angle of $10.3 \pm 4.7^{\circ}$ results in a titanium GF caval angle of $4.1 \pm 5.8^{\circ}$ (Kinney et al., 1997). Therefore, in the present study, the filter is deployed after being tilted and fixed at $10^{\circ}$ with respect to the blood vessel, and the posture was then evaluated. As shown in Fig. 4, since the total length of the GF is $47 \mathrm{~mm}$, angles of $10^{\circ}$ and $4^{\circ}$ correspond to the difference between the center of the blood vessel and the center of the head of $8\left(=47 \tan 10^{\circ}\right) \mathrm{mm}$ and $3 \mathrm{~mm}$, respectively.

- Cases 4-1 and 4-2: The filter is deployed through a catheter in which the axis is not same as that of the blood vessel.

When the deployment sheath is close to the caval wall at the moment of filter release, the sheath slides along the lateral caval wall during filter deployment with the struts 
instantly becoming attached to the adjacent wall. As a result, the filter cannot expand uniformly (Kinney et al., 1997). Therefore, we evaluated the condition in which the filter is deployed through a catheter for which the axis is not same as that of the blood vessel for a distance of $5 \mathrm{~mm}$.

The results were evaluated based on the difference between the center of the blood vessel and the center of the head, and the migration of the head.

\section{Results and discussions}

\subsection{Motion of the deployed filter}

The difference between the center of the blood vessel and the center of the head after deployment of the filter is shown in Fig. 6. This difference indicates the tilt of the filter in the blood vessel. The distribution of the absolute value of the contact force after placement of the filter is shown in Fig. 7. When the difference in Fig. 6 is large (Case 3-2), the contact force in Fig. 7 is large and non-uniform. The ability to calculate the contact force distribution

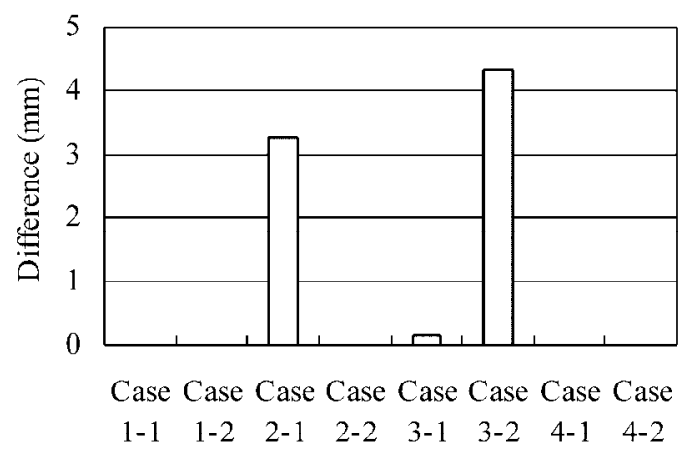

Fig. 6. Difference between the center of the blood vessel and the center of the head after deployment of the filter.

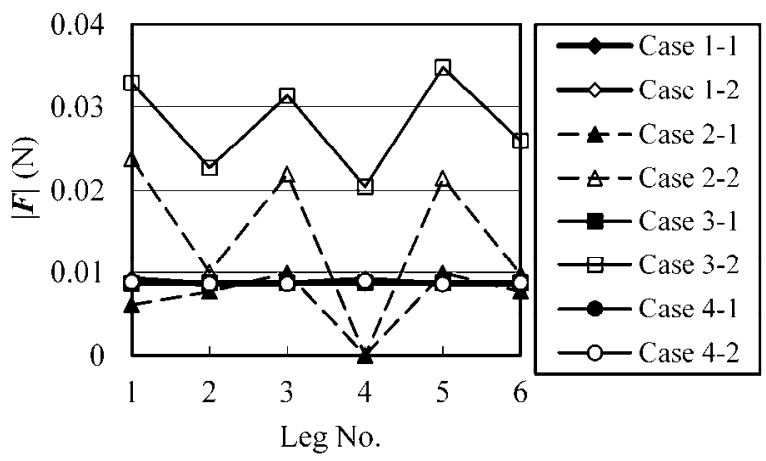

Fig. 7. Distribution of absolute value of contact force $(\boldsymbol{F})$ after placement of filter. 
is one of the advantages of numerical analysis, since it is difficult to determine clinically. In the following section, we described the results for each case in detail.

First, we evaluated the motion of the filter without friction when the axis of the introducer catheter is along the centerline of the blood vessel (Case 1-1). The trajectories of the head and the wire tips are shown in Fig. 8. In this figure, the initial and final positions are indicated by circle and square symbols, respectively. The wire tips expand uniformly from the center to the blood vessel wall in the directions shown by the arrows. As shown in Figs. 6 and 8, the head did not move from the center of the blood vessel and the filter could be deployed normally. Moreover, the final position for the case with friction (Case 1-2) did not change (Fig. 6).

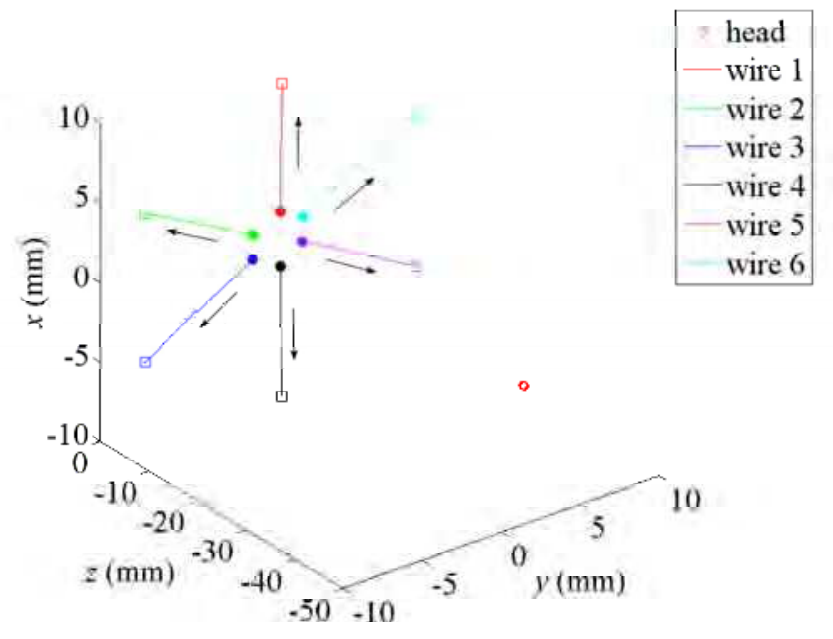

Fig. 8. Trajectories of the head and the tips of the wires (Case 1-1).

The motion of the filter was evaluated for the case in which the filter does not expand uniformly (Cases 2-1 and 2-2). The trajectories of head and the wire tips and appearance of the deployed filter are shown in Figs. 9 and 10, respectively. The transition of the contact force at the wire tips is shown in Fig. 11. The wire indicated by the arrows in Figs. 9 and 10 cannot expand. In Fig. 9, the initial and final positions are shown by the circle and square symbols, respectively. For the case without friction (Case 2-1), the head deviated from the center of the blood vessel (Fig. 9) and tilted and was fixed (Fig. 10). As the filter tilted, the values of all contact force except wire 4 approached closely (Fig. 11 (a)). On the other hand, for the case with friction (Case 2-2), the deviation of the head center of the blood vessel from was small even when one wire could not expand (Fig. 6). Namely, the filter did not move because the friction fixed the filter at the initial contact position. After the fixation, each contact force increased gradually (Fig. 11 (b)).

We evaluated the motion of the filter when the introducer catheter is not aligned with the axis of the vena cava $\left(10^{\circ}\right)$ (Case 3$)$. The transition of the difference between the center of the head and the center of the blood vessel, and appearance of the deployed filter are shown in Figs. 12 and 13, respectively. For the case without friction (Case 3-1), the head approached 
the center of the blood vessel. On the other hand, for the case with friction (Case 3-2), the inserted filter tilted (Fig. 12) and stopped in the tilted position (Fig. 13). The angle of the tilt (difference: $4.3 \mathrm{~mm}$ ) was similar to that for reported clinical results (Kinney et al., 1997). Moreover, when the filter was tilted, the contact force was large and non-uniform (Fig. 7). The transition of the contact force at the wire tips are shown in Fig. 14. The contact force increased gradually for the case with friction (Fig. 14 (b)) similarly to Fig. 11 (b), although the tilt with friction was larger than that without the friction contrary to Case 2. The transition of the distance between the wire tips and the center of the blood vessel is shown in Fig. 15. In this figure, the distance of the tip of wire 4 from the center of the blood vessel, as indicated by the arrow, first increased and then decreased abruptly. This phenomenon

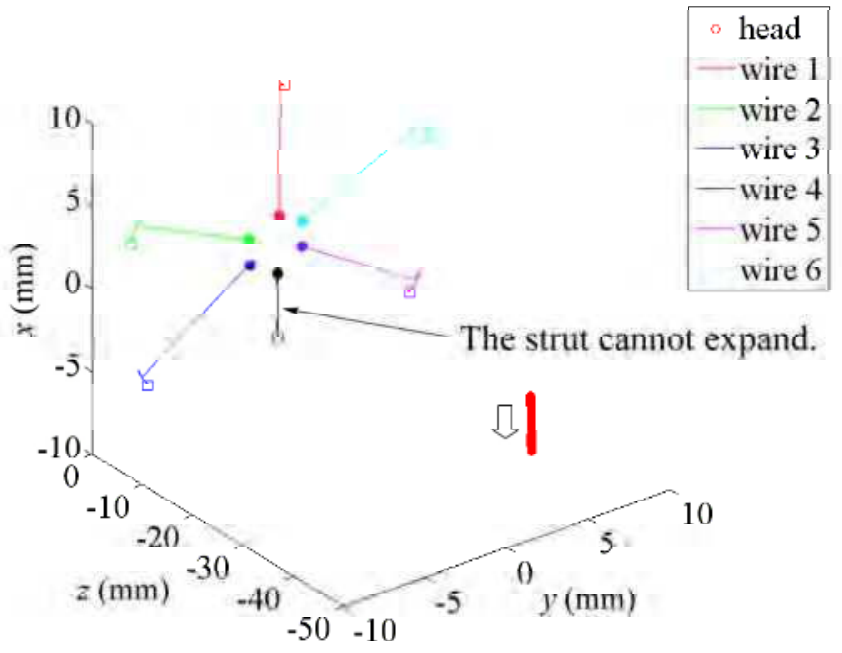

Fig. 9. Trajectories of the head and the tips of the wires (Case 2-1). The filter does not expand uniformly.

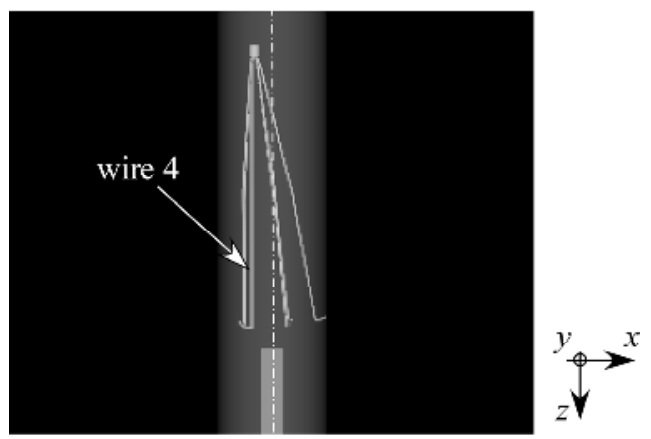

Fig. 10. Filter after deployment (Case 2-1). The filter does not expand uniformly. The arrow indicates a wire that cannot expand. 


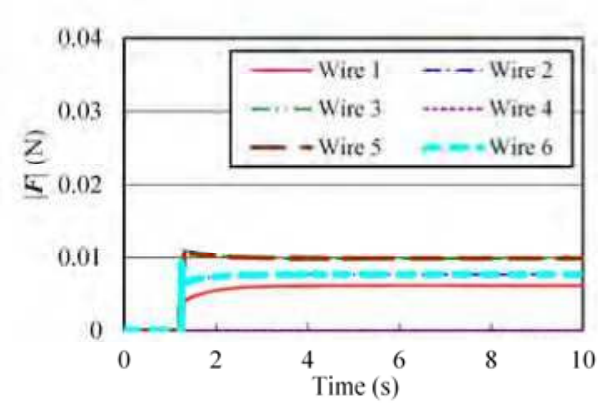

(a) Without friction

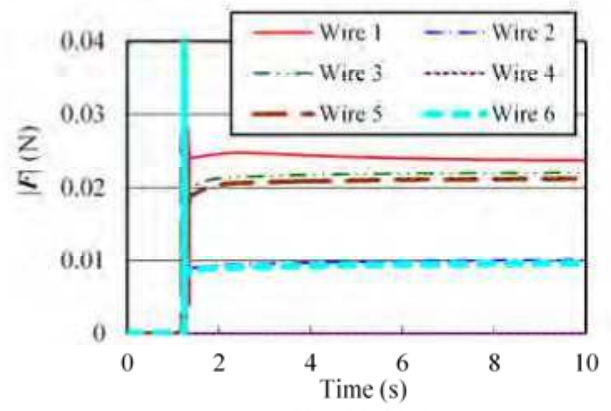

(b) With friction

Fig. 11. Transition of the contact force $(\boldsymbol{F})$ at the wire tip (Cases 2-1 and 2-2). The filter does not expand uniformly.

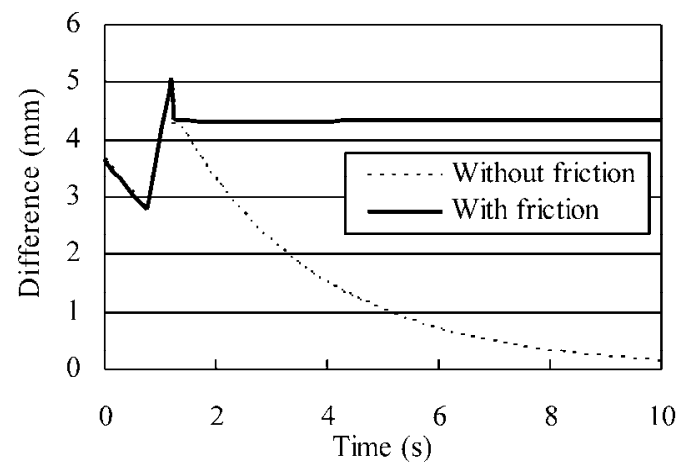

Fig. 12. Transition of the difference between the center of the head inserted through a tilted catheter and the center of the blood vessel (Cases 3-1 and 3-2).
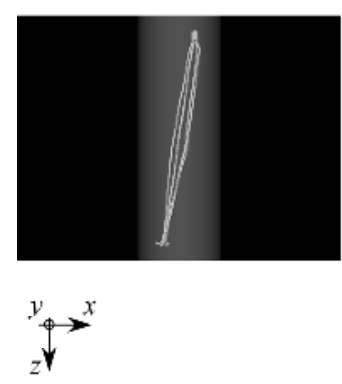

(a) immediately after placement

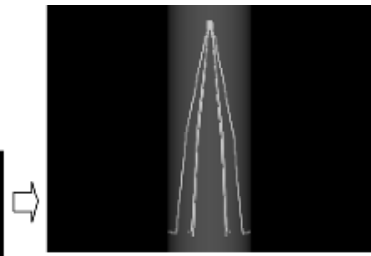

Without friction

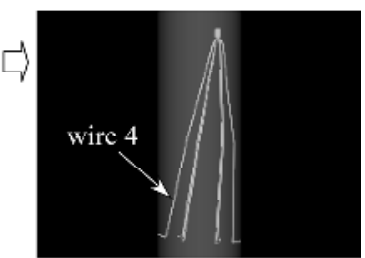

With friction

(b) after placement

Fig. 13. Placement of the filter inserted through a tilted catheter (Cases 3-1 and 3-2). 


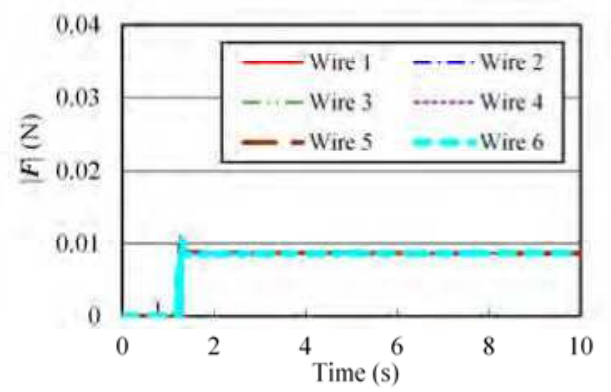

(a) Without friction

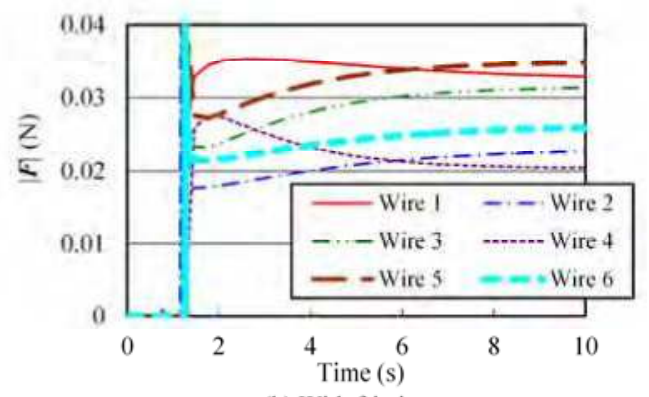

(b) With friction

Fig. 14. Transition of the contact force $(\boldsymbol{F})$ inserted through a tilted catheter (Cases 3-1 and 3-2).

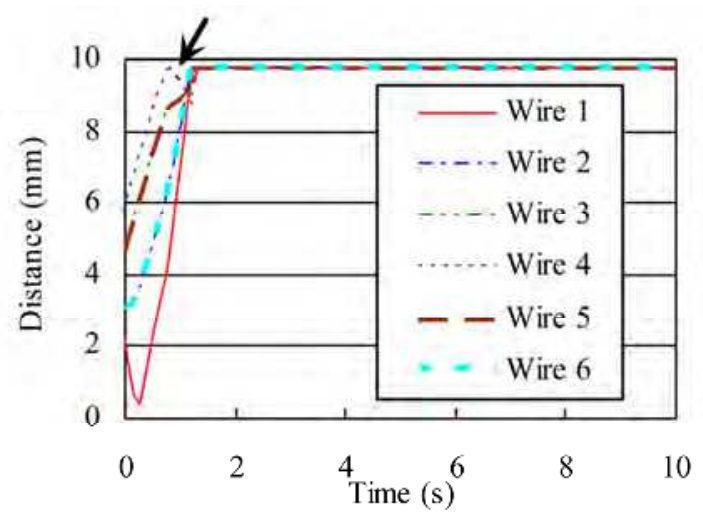

Fig. 15. Transition of the distance between the wire tips and the center of the blood vessel (Case 3-2). The filter was inserted through a tilted catheter.

indicates rebounding of the wire on the blood vessel. Moreover, after rebounding of the wire, all six wires came into contact with the blood vessel wall at the same time. Therefore, the tilt of the filter became smaller than that of the catheter.

When the axis of the catheter is not same as that of the blood vessel (5 mm) (Cases 4-1 and 42), the tilts of the filters with or without friction are small, as shown in Figs. 6 and 16. The transition of the distance between the wire tips and the center of the blood vessel are shown in Fig. 17. In this figure, after wire 1 (indicated by the arrow) first contacted the vessel wall and then rebounded, all six wires came into contact with the vessel wall at the same time. Therefore, similar to Fig. 13, the tilt of the filter was small (Case 4). Actually, the wire tip may bite and be fixed at the first contact point without rebounding. In this study, the force to keep contact was not defined. Therefore, it is necessary to investigate the contact force between the hook and the blood vessel experimentally.

As shown above, the difference between the center of the blood vessel and the center of the head after deployment of the filter is large when the filter does not expand uniformly or when the filter is inserted through a tilted catheter. Although it is unclear what constitutes a 
clinically significant filter tilt, in vitro studies suggested that the clot-trapping ability of the GF is reduced at angle of $14^{\circ}$ or greater (Katsamouris et al., 1988, as cited in Rogers et al., 1998). This angle corresponds to a difference between the center of the blood vessel and the center of the head of $12 \mathrm{~mm}$. As shown in Fig. 6, the maximum difference in the present study is $4.3 \mathrm{~mm}$, which is smaller than this value. However, large tilt may occur for a variety of reasons. For example, the filter which cannot expand uniformly (Case 2) may be deployed through an inclined catheter (Case 3). Furthermore, although the difference between the center of the blood vessel and the center of the head was small for a catheter for which the axis was not the same as that of the blood vessel (Cases 4), the difference may become larger than that in Case 3 when the catheter tilts (Case 3) and close to the caval wall (Case 4) at the same time.
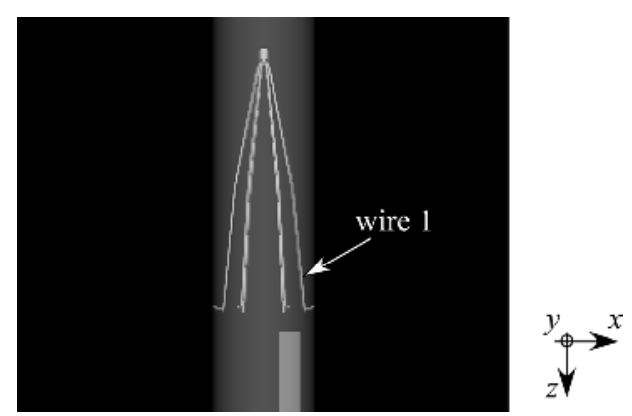

Fig. 16. Filter after deployment through a catheter for which the axis is not same as that of the blood vessel (Case 4-1).

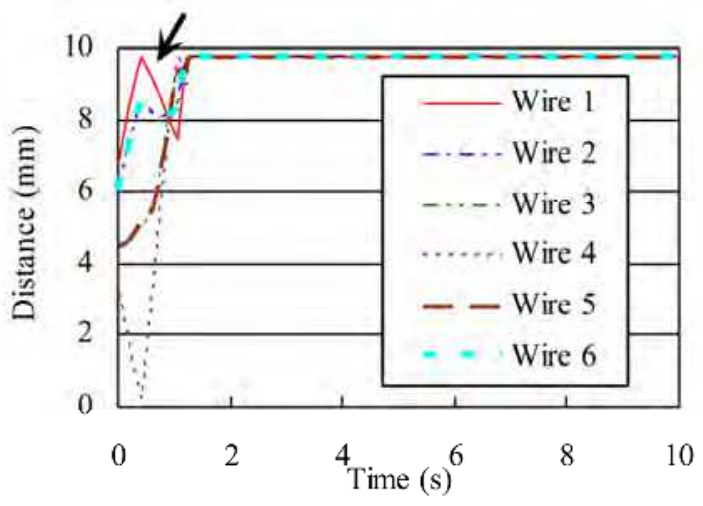

Fig. 17. Transition of the distance between the wire tips and the center of the blood vessel (Case 4-2). The axis of the catheter is not same as that of blood vessel.

\subsection{Migration of the filter due to blood flow}

Apart from the ability to precisely position and orient the filter, it is also important that it undergoes a minimal amount of migration. In this section, we evaluate the migration of the 
head for a fixed time under a constant force after deploying the filter, as described in the previous sections. The migration of the head for a fixed time (60 s) under a constant force along the $z$-axis is shown in Fig. 18. The migration was large in Cases 2-2 and 3-2. Significant migration is usually defined as caudal or cranial movement in excess of $1 \mathrm{~cm}$ (Streiff, 2000). Similarly, for example, Greenfield et al. defined as significant a change in vertical position of $9 \mathrm{~mm}$ or more at 30 days (Greenfield et al., 1991). However, the results of the present study are much smaller than these values.

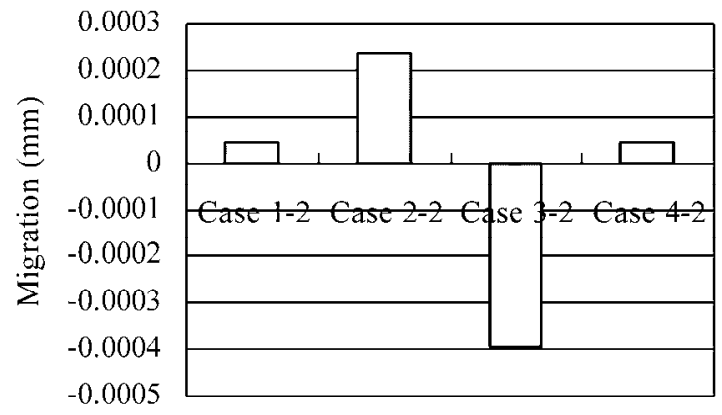

Fig. 18. Migration of the head for a fixed time (60 s) under a constant force.

In the present study, using Eqs. (8) and (9), the friction force is defined by springs at the contact points. Therefore, the friction force can change according to the spring constant. In this model, since there are six springs for which $K_{\mathrm{f}}=32 \mathrm{~N} / \mathrm{mm}$, we obtain a migration of $3 \times 10^{-5} \mathrm{~mm}$ when $2 \mathrm{G}$ is applied to the 0.3 -g filter $(6 \mathrm{mN})$. This value is similar to the values shown in the figure (Cases 1-2 and 4-2). In the future, it will be necessary to determine this parameter $\left(K_{\mathrm{f}}\right)$ exactly. Moreover, the filter will move when the friction force exceeds a certain value, and these effects must be considered. The contact force distribution is shown in Fig. 19. Comparing this figure with Fig. 7, the distribution was changed. The concentration of the contact force may cause the loosening of the hook actually.

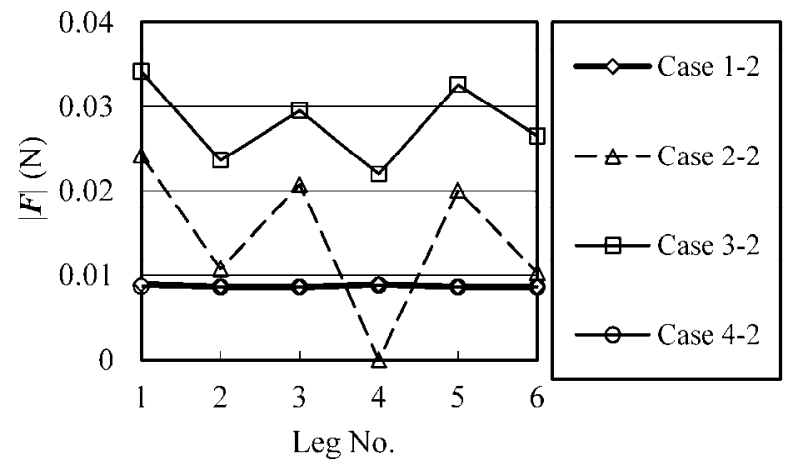

Fig. 19. Distribution of absolute value of contact force $(\boldsymbol{F})$ for a fixed time (60 s) under a constant force. 


\subsection{Evaluation of parameters}

As mentioned above, in addition to the GF, several other types of inferior vena cava filters have been developed. For example, although the Simon-Nitinol filter become popular because of its lower profile, a caval thrombosis rate of up to $50 \%$ has been reported for this filter (Decousus et al., 1998; Hawkins \& Al-Kutoubi, 1992; Kim et al., 1992; Grassi et al., 1992; Simon et al., 1989, as cited in Swaminathan et al., 2006). In order to quantitatively compare different types of filters, numerical analysis is a very effective method because various filters can be compared under the same simulation condition, for example, the same vessel shape. Asymmetry of the limbs increases the possibility of impairment of filtration in the area of wider limb spread (Greenfield et al., 1991). However, theoretically, eccentric placement might be anticipated to impair performance, although no pulmonary embolisms have been linked to this finding (Streiff, 2000). Therefore, it is necessary to couple the present results with computational fluid dynamics results.

It is necessary to improve the simulation model in order to reproduce the motion in surgery. Although, in the present catheter simulator, the blood vessel is an artery, the filter is applied to a vein. In the present study, we used the same parameters in both conditions. However, since the mechanical properties of the artery and the vein are different, it would be necessary to measure the mechanical properties of the vein experimentally and to verify Eqs. (7), (8), and (9). Moreover, the diameter of the blood vessel model used in the present study is constant. However, there is some possibility of one of the limbs of the filter entering a tributary vein (Boston Scientific, 2007). Moreover, when the inner diameter is different, the applied force changes. Therefore, it is necessary to model the shape of the blood vessel exactly. Moreover, when the filter is released from the catheter, the friction between the catheter and the filter may cause the filter to tilt.

\section{Conclusions}

In this chapter, we describe the evaluation of the effects of the parameters of the simulation model on the deployment of the Greenfield filter. The results are as follows.

1. When the introducer catheter is not aligned with the axis of the vena cava, the inserted filter becomes tilted.

2. When the filter does not expand uniformly, the inserted filter also becomes tilted.

3. The friction between the filter and the blood vessel wall affects the tilt of the filter.

This simulation method can be used for surgical planning, intra-operative assistance, and the design of new filters.

\section{Acknowledgment}

The present study was supported by KAKENHI through a Grant-in-Aid for Young Scientists (B) (22700485).

\section{References}

Ando, M. \& Kuribayashi, S. (2000). Placement of Inferior Vena Cava Filter: Indication, Technique and Results. Japanese Journal of Phlebology, Vol.11, No.1, pp.93-98, ISSN 0915-7395 (in Japanese) 
Boston Scientific (2007). Instructions for Use, Greenfield Vena Cava Filter System (5th edition) (in Japanese)

Greenfield, L.J.; Cho, K.J. \& Tauscher, J.R. (1990). Evolution of Hook Design for Fixation of the Titanium Greenfield Filter. Journal of Vascular Surgery, Vol.12, No.3, pp.345-353, ISSN 0741-5214

Greenfield, L.J.; Cho, K.J.; Proctor, M.; Bonn, J.; Bookstein, J.J.; Castaneda-Zuniga, W.R.; Cutler, B.; Ferris, E.J.; Keller, F.; McCowan, T.; Pais, S.O.; Sobel, M.; Tisnado, J. \& Waltman, A.C. (1991). Results of a Multicenter Study of the Modified Hooktitanium Greenfield Filter. Journal of Vascular Surgery, Vol.14, No.3, pp.253-257, ISSN 0741-5214

Hahn, J.K.; Kaufman, R.; Winick, A.B.; Carleton, T.; Park, Y.; Lindeman, R.; Oh, K.M.; AlGhreimil, N.; Walsh, R.J.; Loew, M. \& Sankar, S. (1998). Training Environment for Inferior Vena Caval Filter Placement, In: Studies in Health Technology and Informatics, Westwood, J.D.; Hoffman, H.M.; Stredney, D. \& Weghorst, S.J. (Eds.), Vol.50, pp.291-297, IOS Press, ISBN 978-90-5199-386-8, Amsterdam, Netherlands

Kinney, T.B.; Rose, S.C.; Weingarten, K.E.; Valji, K.; Oglevie, S.B. \& Roberts, A.C. (1997). IVC Filter Tilt and Asymmetry: Comparison of the Over-the-wire Stainless-steel and Titanium Greenfield IVC Filters. Journal of Vascular and Interventional Radiology, Vol.8, No.6, pp.1029-137, ISSN 1051-0443

Nara, S.; Moteki, K.; Kameda, T.; Ishitobi, K.; Kodera, K. \& Kimura, M. (1995). Therapeutic Efficacy of Percutaneous Placement of the Inferior Vena Caval Filter, Japanese Journal of Phlebology, Vol.6, No.1, pp.39-45, ISSN 0915-7395 (in Japanese)

Petrini, L.; Migliavacca, F.; Massarotti, P.; Schievano, S.; Dubini, G. \& Auricchio, F. (2005). Computational Studies of Shape Memory Alloy Behavior in Biomedical Applications, Transaction of the ASME, Journal of Biomechanical Engineering, Vol.127, No.4, pp.716-725, ISSN 0148-0731

Rogers, F.B.; Strindberg, G.; Shackford, S.R.; Osler, T.M.; Morris, C.S.; Ricci, M.A.; Najarian, K.E.; D'Agostino, R. \& Pilcher, D.B. (1998). Five-year Follow-up of Prophylactic Vena Cava Filters in High-risk Trauma Patients, Archives of Surgery, Vol.133, No.4, pp.406-411, ISSN 0096-6908

Streiff, M.B. (2000). Vena Caval Filters: a Comprehensive Review. Blood, Vol.95, No.12, pp.3669-3677, ISSN 1528-0020

Swaminathan, T.N.; Hu, H.H. \& Patel, A.A. (2006). Numerical Analysis of the Hemodynamics and Embolus Capture of a Greenfield Vena Cava Filter, Transaction of the ASME, Journal of Biomechanical Engineering, Vol.128, No.3, , pp.360-370, ISSN 0148-0731

Tagori. T. \& Arakawa, C. (1989). Fluids Engineering, University of Tokyo Press, ISBN 4-13062124-6, Tokyo, Japan (in Japanese)

Takashima, K.; Ota, S.; Ohta, M.; Yoshinaka, K. \& Ikeuchi, K. (2006). Development of Computer-based Simulator for Catheter Navigation in Blood Vessels (1st Report, Evaluation of Fundamental Parameters of Guidewire and Blood Vessel). Transactions of the Japan Society of Mechanical Engineers, Series C, Vol.72, No.719, pp.2137-2145, ISSN 0387-5024 (in Japanese)

Takashima, K.; Shimomura, R.; Kitou, T.; Terada, H.; Yoshinaka, K. \& Ikeuchi, K. (2007a). Contact and Friction between Catheter and Blood Vessel. Tribology International, Vol.40, Issue 2, pp.319-328, ISSN 0301-679X 
Takashima, K.; Ota, S.; Ohta, M.; Yoshinaka, K. \& Mukai, T. (2007b). Development of Computer-based Simulator for Catheter Navigation in Blood Vessels (2nd Report, Evaluation of Fundamental Parameters of Guidewire and Blood Vessel). Transactions of the Japan Society of Mechanical Engineers, Series C, Vol.73, No.735, pp.2988-2995, ISSN 0387-5024 (in Japanese)

Takashima, K.; Ohta, M.; Yoshinaka, K.; Mukai, T. \& Ota, S. (2009). Catheter and Guidewire Simulator for Intravascular Surgery (Comparison between Simulation Results and Medical Images), The World Congress on Medical Physics and Biomedical Engineering (WC2009), pp.128-131, ISBN 978-3-642-03897-6, Munich, Germany, September 7-12, 2009

Yamamura, N.; Himeno, R. \& Makinouchi, A. (2003). Development of Catheter Simulator. Proceedings of Riken Symposium on Computational Biomechanics, pp.136-144, Tokyo, Japan, May 27-28, 2003 (in Japanese) 


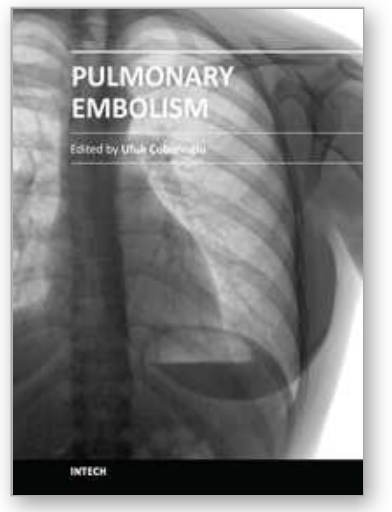

\author{
Pulmonary Embolism \\ Edited by Dr. Ufuk Çobanoğlu
}

ISBN 978-953-51-0233-5

Hard cover, 236 pages

Publisher InTech

Published online 14, March, 2012

Published in print edition March, 2012

Pulmonary embolism is a serious, potentially life-threatening cardiopulmonary disease that occurs due to partial or total obstruction of the pulmonary arterial bed. Recently, new improvement occurred in the diagnosis and treatment of the disease. The aim of this disease is to re-review pulmonary embolism in the light of new developments. In this book, in addition to risk factors causing pulmonary embolus, a guide for systematic approaches to lead the risk stratification for decision making is also presented. In order to provide a maximum length of active life and continuation of functional abilities as the aim of new interventional gerontology, the risk factors causing pulmonary embolus in elderly individuals are evaluated, and the approach to prevention and treatment are defined. The risk of the development of deep vein thrombosis and pulmonary embolism, combined with obesity due to immobility, the disease of this era, irregular and excessive eating, and treatment management are highlighted. Non-thrombotic pulmonary emboli are also covered and an attempt is made to constitute an awareness of this picture that can change the treatment and prognosis of the disease to a considerable extent. In addition to the pathophysiological definition of pulmonary embolus, the priority goal of quick and definitive diagnosis is emphasized, and diagnostic strategies are discussed in the book. A numerical analysis of the vena cava filters, which is a current approach to prevent pulmonary emboli recurrences, is presented in the last chapter.

\title{
How to reference
}

In order to correctly reference this scholarly work, feel free to copy and paste the following:

Kazuto Takashima, Koji Mori, Kiyoshi Yoshinaka and Toshiharu Mukai (2012). Numerical Analysis of the Mechanical Properties of a Vena Cava Filter, Pulmonary Embolism, Dr. Ufuk Çobanoğlu (Ed.), ISBN: 978-95351-0233-5, InTech, Available from: http://www.intechopen.com/books/pulmonary-embolism/numericalanalysis-of-the-mechanical-properties-of-a-vena-cava-filter

\section{INTECH}

open science | open minds

\section{InTech Europe}

University Campus STeP Ri

Slavka Krautzeka 83/A

51000 Rijeka, Croatia

Phone: +385 (51) 770447

Fax: +385 (51) 686166

\section{InTech China}

Unit 405, Office Block, Hotel Equatorial Shanghai

No.65, Yan An Road (West), Shanghai, 200040, China 中国上海市延安西路65号上海国际贵都大饭店办公楼 405 单元 Phone: +86-21-62489820

Fax: +86-21-62489821 
www.intechopen.com 
(C) 2012 The Author(s). Licensee IntechOpen. This is an open access article distributed under the terms of the Creative Commons Attribution 3.0 License, which permits unrestricted use, distribution, and reproduction in any medium, provided the original work is properly cited. 